\title{
Mortality in Dutch hospitals: Trends in time, place and cause of death after admission for myocardial infarction and stroke. An observational study
}

\author{
Laurentius CJ Slobbe*1, Onyebuchi A Arah ${ }^{1,4}$, Agnes de Bruin ${ }^{2}$ and \\ Gert P Westert 1,3
}

\begin{abstract}
Address: ${ }^{1}$ Department of Public Health and Healthcare, National Institute for Public Health and the Environment, Antonie van Leeuwenhoeklaan 9, PO Box 1, 3721 MA Bilthoven, The Netherlands, ${ }^{2}$ Department of Health and Care, Statistics Netherlands, Prinses Beatrixlaan $428,2273 \mathrm{XZ}$ Voorburg, The Netherlands, ${ }^{3}$ Faculty of Social and Behavioural sciences, Tilburg University, Warandelaan 2, PO Box 90153 , 5000 LE Tilburg, The Netherlands and ${ }^{4}$ Department of Social Medicine, Academic Medical Center, University of Amsterdam, Meibergdreef 9, PO Box 22700, 1100 DE Amsterdam, The Netherlands
\end{abstract}

Email: Laurentius CJ Slobbe* - lany.slobbe@rivm.nl; Onyebuchi A Arah - o.a.arah@amc.uva.nl; Agnes de Bruin - abun@cbs.nl; Gert P Westert - gert.westert@rivm.nl

* Corresponding author

Published: 4 March 2008

BMC Health Services Research 2008, 8:52 doi:10.1186/1472-6963-8-52
Received: 22 June 2007

Accepted: 4 March 2008

This article is available from: http://www.biomedcentral.com/l472-6963/8/52

(c) 2008 Slobbe et al; licensee BioMed Central Ltd.

This is an Open Access article distributed under the terms of the Creative Commons Attribution License (http://creativecommons.org/licenses/by/2.0), which permits unrestricted use, distribution, and reproduction in any medium, provided the original work is properly cited.

\begin{abstract}
Background: Patterns in time, place and cause of death can have an important impact on calculated hospital mortality rates. Objective is to quantify these patterns following myocardial infarction and stroke admissions in Dutch hospitals during the period 1996-2003, and to compare trends in the commonly used 30-day in-hospital mortality rates with other types of mortality rates which use more extensive follow-up in time and place of death.

Methods: Discharge data for all Dutch admissions for index conditions (1996-2003) were linked to the death certification registry. Then, mortality rates within the first 30,90 and 365 days following admissions were analyzed for deaths occurring within and outside hospitals.

Results: Most deaths within a year after admission occurred within 30 days (60-70\%). No significant trends in this distribution of deaths over time were observed. Significant trends in the distribution over place of death were observed for both conditions. For myocardial infarction, the proportion of deaths after transfer to another hospital has doubled from 1996-2003. For stroke a significant rise of the proportion of deaths outside hospital was found. For MI the proportion of deaths attributed to a circulatory disease has significantly fallen ovtime. Seven types of hospital mortality indicators, different in scope and observation period, all show a drop of hospital mortality for both $\mathrm{Ml}$ and stroke over the period 1996-2003. For stroke the observed absolute reduction in death rate increases for the first year after admission, for $\mathrm{Ml}$ the observed drop in 365-day overall mortality almost equals the observed drop in 30-day in hospital mortality over 1996-2003.

Conclusion: Changes in the timing, place and causes of death following admissions for myocardial infarction and stroke have important implications for the definitions of in-hospital and post-admission mortality rates as measures of hospital performance. Although necessary for understanding mortality patterns over time, including within mortality rates deaths which occur outside hospitals and after longer periods following index admissions remain debatable and may not reflect actual hospital performance but probably mirrors transfer, efficiency, and other health care policies.
\end{abstract}




\section{Background}

Mortality after admission is seen as an important indicator of hospital performance, and forms part of several sets of quality indicators $[1,2]$. Some systems of measuring hospital performance even rely exclusively on post-admission mortality rates to rank hospital quality [3]. However, there are several pitfalls when it comes to calculating these indicators. The first question to consider is the influence of trends in place and time of death on hospital mortality statistics. An observed decline in hospital mortality after a myocardial infarction (MI) or stroke could indicate better care, but could also point to earlier discharge or to an increased transfer between hospitals, with death occurring after discharge or transfer. For Canada it has been shown that excluding transfer cases changes performance ranking for MI [4]. A related problem is the risk of administrative errors related to transfer. An American study revealed that double counting of patients in routine statistics occurred in $10-15 \%$ of all inter-hospital transfer cases, which significantly influenced both hospitalization and mortality rates [5]. It has been argued that the influence of transfer on hospital mortality statistics has grown in recent years, due to the shortening of length of stay [6]. An analysis of UK data has shown that the proportion of 30-day mortality falling within the initial admission has actually decreased over time[7].

A second question is how to attribute deaths after admission to the cause of death. Hospital mortality rates as a measure of quality are usually evaluated in terms of the direct cause of morbidity, but this need not be the true cause of death. Country statistics of deaths are in most cases based on national death records. These often take a different view of the cause of death by taking the patient history into account, before admission to the hospital. This opens up room for discrepancy and conflicting interpretations of death rates. Studies in Denmark [8] and the UK [9] have shown that a fairly large proportion of deaths after a hospitalization for MI or stroke are attributed to different causes in death records.

A third question associated with the use of mortality quality indicators is to what extent patients should be followed up after discharge, especially if hospital discharge registrations are not linked with each other or with a national death certificate register, as is the case in the Netherlands. Without such a link-up the administrative burden of follow-up after discharge is high, with large differences in the effort hospitals put into this follow-up. For example, the Dutch Health Care Inspectorate (IGZ) asks hospitals to collect data on 30-day mortality after admission for myocardial infarction. However, in the last publicized outcomes for this indicator, [10] about $40 \%$ of hospitals could not provide data on mortality after discharge. An in- depth analysis of five Dutch hospitals commissioned by the IGZ [11] revealed that there were also large differences in the way hospitals interpreted the necessary follow-up after discharge or transfer, with some settling for including transfers, others ignoring these, while others also included death outside their hospital.

The goal of this study is to assess the importance of these three questions for the computation of mortality indicators after discharge in the Netherlands for two conditions: myocardial infarction and stroke. The first question, the influence of trends in place and time of death on hospital mortality statistics, will be addressed by classifying death cases after an hospital admission for these conditions according to time and place of death. The second question, how to attribute deaths after admission to the cause of death will be addressed by comparing the cause of hospital admission with the cause of death on the death certificate. The third question, the extent to which patients should be followed up for the computation of mortality indicators, will be addressed by computing seven different mortality indicators which differ in the extension of the follow-up and the associated administrative burden.

\section{Methods}

Records from the Dutch hospital discharge register (LMR) for the period 1995-2003 were linked to the population register by Statistics Netherlands. The hospital discharge register is maintained by Prismant Utrecht. This register contains discharge data for all Dutch general and academic hospitals, and contains information on patientcharacteristics (date of birth, gender, place of residence) and episode characteristics (discharge diagnosis, date of admission and discharge). More than $87 \%$ of all hospital discharges in this register were successfully linked at the micro-level to the population register[12] The linkage techniques and the reliability and usability of this dataset for statistical research have been described elsewhere[13,14].

In addition this combined set was linked to the Dutch death certificate register, maintained by Statistics Netherlands. This was necessary to establish the time and the cause of death. This linkage was facilitated by the fact that both datasets use the same personal identifier, thus yielding almost $100 \%$ linkage rates after excluding those who emigrated abroad since admission to the hospital.

Approval for the use of the anonymized patient data was covered by a general agreement between Statistics Netherlands and Prismant. In addition, the Dutch association of hospitals (NVZ) approved the use of the hospital registration data for this study. No separate ethical approval was necessary for the use of these data. 
This combined dataset was used to analyze the place, time, cause and rate of death within the first year after an index-admission for myocardial infarction or stroke among people aged 35 years and above. Index cases were defined using the main discharge diagnosis. The LMR uses the ICD9-CM (Dutch Clinical modification[15]) to register discharge diagnosis. Myocardial infarction was defined as ICD9-CM code 410, stroke as ICD9-CM code 431-434 and code 436.

Inclusion criteria for cases in the analysis were (a) having a principal diagnosis for myocardial infarction or stroke, (b) being 35 years or older at the end of the year of admission. Exclusion criteria were: (1) having another admission for the specified condition within 365 days before the index-admission; (2) having no hospital data available for any part of the period between 365 days before and 365 days after index admission; (3) ambiguously identified patients in the linked set in the year before and after the index-admissions, in order to avoid having administrative twins or émigrés; (4) if the date of mortality on the death certificate preceded the date of admission (as was noticed for $11 \mathrm{MI}$ and 6 stroke patients). The second exclusion criterion mentioned above was necessary in order to verify the place of death (inside or outside the hospital) and to verify that an index-admission was not preceded within a year by a previous admission. This criterion implied that the first and last year of the dataset were used for verification purposes only, and did not yield any index-admissions. The third criterion led to the exclusion of $5 \%$ of previously selected cases.

Table 1 sums up some characteristics for selected indexcases.

For all cases, the time to death was computed by subtracting the date of admission to a hospital from the date of mortality on the death certificate. All selected indexadmissions were assigned a time of death class (within 029 days after admission, within 30-89 days after admission, within 90-365 days after admission), counting the date of admission as zero. For this analysis only those index cases resulting in death within a year of admission were used. We used chi-squared tests to detect significant correlations between year of admission and time of death and place of death categorizations.

All cases were also assigned a place of death class using any of four groupings:

-deaths within the index-admission

-deaths within a subsequent admission in the same hospital as the index-admission -deaths that occurred in a different hospital

-deaths outside hospital

The cause of death was established using the primary cause registered on the death certificate, using the ICD-10 classification. Causes of death were grouped into three:

-cause of death attributed to cause of index-admission

-cause of death attributed to a circulation disorder other than index-condition

-deaths due to other causes

The difference in classification systems used in our morbidity data (ICD-9) and mortality data (ICD-10) caused a minor problem in establishing the correspondence between the cause of mortality and the index-condition for stroke because no exact translation could be made. We, therefore, decided to compare the outcomes with a slightly broader ICD-10 definition of stroke [I61-I69], also including indeterminate types. We used chi-square analysis to detect significant correlations between year of admission and cause of death.

In our data follow-up of patients was possible for a year after discharge. To show the effect of including or excluding different types of follow-up on mortality rates, we calculated seven different types of mortality rates, for each year in our dataset. Thirty-day mortality within the initial admission was easily calculated in addition to three period (30-, 90- and 365-day) rates were calculated for deaths in the hospital setting only (including transfers and readmissions) and for deaths outside the hospital. The denominator for each rate was the total number of admissions fulfilling index-conditions, including those still alive 365 days after the start of the initial admission. Rates were standardized for age and sex using the composition of the Dutch clinical hospital population in the year 2000.

\section{Results}

Actual linkage rates of hospital discharge records to population register data were somewhat higher than average for the selected cases. Of all admissions in 1996-2003 for AMI age [35-74] 88.9\% could be linked, for 75+ this was $93.2 \%$. For stroke, linkage rates were somewhat lower, with $88.1 \%$ for $35-74$ age category and $88.9 \%$ for those aged $75+$ (Table 1$)$.

For the period 1996-2003 we included 32,990 deaths after admission for MI and 47,393 deaths after admission for stroke in our analysis. Of the MI cases $67.9 \%$ of those aged 35-74 died within the first thirty days after admis- 
Table I: Characteristics of patients included in analysis \& general characteristics Dutch hospitals \& Dutch population

\begin{tabular}{|c|c|c|c|c|}
\hline \multicolumn{5}{|l|}{ Admission characteristics* } \\
\hline period & \multicolumn{4}{|l|}{$1996-2003$} \\
\hline diagnosis & \multicolumn{2}{|c|}{ Myocardial infarction } & \multicolumn{2}{|l|}{ Stroke } \\
\hline agegroup & [35-74] & {$[75+]$} & [35-74] & {$[75+]$} \\
\hline Number of hospital admissions within LMR (before linking) & 151,104 & 60,853 & 104,222 & 85,098 \\
\hline Number of hospital admissions within linked LMR & 134,272 & 56,737 & 91,769 & 75,656 \\
\hline link yield $(\%)$ & 88.9 & 93.2 & 88.1 & 88.9 \\
\hline Index cases selected before application mortality restriction & 111,204 & 49,653 & 75,424 & 67,118 \\
\hline Index cases selected after application mortality restriction (death within a year of admission) & 13,662 & 19,328 & 16,089 & 31,304 \\
\hline \multicolumn{5}{|l|}{ Characteristics index-cases } \\
\hline Mean age & 60.4 & 81.0 & 63.1 & 81.7 \\
\hline Proportion male (\%) & 74.5 & 49.9 & 60.7 & 41.8 \\
\hline Length of stay (days) & 8.3 & 9.6 & 14.8 & 21.6 \\
\hline Decrease length of stay 1996-2003 (\%) & -10.2 & -7.2 & -29.6 & -30.4 \\
\hline
\end{tabular}

General characteristics Dutch hospitals $†$

\begin{tabular}{lrr}
\hline & & \\
& year & 1996 \\
Number of hospitals (general, academic, categorical) & 148 & 2003 \\
Number of beds (clinical \& day care) & 58,135 & 52,292 \\
Number of clinical admissions (thousands) & 1,589 & 1,602 \\
Number of clinical hospital days (thousands) & 15,531 & 12,757 \\
Number of day care admissions (thousands)§ & 705 & 1,221 \\
Workforce (full time equivalents, thousands) & 139 & 175 \\
\hline
\end{tabular}

\section{General characteristics Dutch population ${ }^{\dagger}$}

average population size ages $35-74$

average population size ages $75+$

$\begin{array}{rrr}\text { year } & & \\ 1996 & 2003 \\ 7.1 & 7.9 \\ 0.9 & 1.0 \\ & \\ 15.1 & 15.4 \\ 45.4 & 39.8\end{array}$

* source: this study

t source: CBS [2I]

$\ddagger$ standardized on Dutch population I-I-2000.

§ source: LMR. Prismant Utrecht

sion, compared to total deaths within a year. For those aged $75+$ this was $66.1 \%$. For stroke age differences were larger with $67.6 \%$ dying within 30 days for ages $35-74$ and $60.2 \%$ for ages $75+$. These proportions are all stable over time: no significant differences between years were detected over the period 1996-2003.

Table 2 lists the breakdown of MI deaths in the different time of death and place of death classes and the year of admission, (given in two-year bands). Table 3 gives a similar breakdown for stroke. Chi-squared tests were used to detect significant trends over time, these are indicated within the tables.
For MI the analysis points to a growing importance of 'other hospitals' as death location for MI, especially for 30-day mortality. In 1996-1997 about 5.9\% of the 30-day mortality after MI for ages 35-74 occurred in a hospital different from that of the initial intake, in 2002-2003 this proportion had significantly risen to $10.9 \%$. This rise was at the expense of 30-day mortality within the initial admission, the proportion of which fell from $86.8 \%$ to $79.7 \%$ over the same period. For ages $75+$ a similar trend is found, but somewhat less strong, although still significant.

No significant changes were detected for MI for other death locations or different distances between time of admission 
Table 2: Dutch in-hospital mortality for myocardial infarction 1996-2003: deaths tabulated by age and place of death within 30, 90 and 365 days of admission

\begin{tabular}{|c|c|c|c|c|c|c|c|c|c|c|}
\hline \multirow[b]{2}{*}{ Time after admission } & \multicolumn{2}{|c|}{$\begin{array}{r}\text { Deaths during initial } \\
\text { admission }\end{array}$} & \multicolumn{2}{|c|}{$\begin{array}{l}\text { Deaths in same } \\
\text { hospital. during } \\
\text { subsequent } \\
\text { admission }\end{array}$} & \multicolumn{2}{|c|}{$\begin{array}{r}\text { Deaths in a different } \\
\text { hospital }\end{array}$} & \multicolumn{2}{|c|}{$\begin{array}{r}\text { Deaths outside } \\
\text { hospital }\end{array}$} & \multicolumn{2}{|c|}{ All locations } \\
\hline & $\mathbf{N}$ & $\%$ & $\mathbf{N}$ & $\%$ & $\mathbf{N}$ & $\%$ & $\mathbf{N}$ & $\%$ & $\mathbf{N}$ & $\%$ \\
\hline \multicolumn{11}{|l|}{ Ages 35-74 } \\
\hline deaths in 0-29 days & $*$ & & & & $*$ & & & & & \\
\hline $1996-1997$ & 2,257 & 86.8 & 68 & 2.6 & 153 & 5.9 & 123 & 4.7 & 2,601 & 100.0 \\
\hline $1998-1999$ & 1,967 & 82.1 & 69 & 2.9 & 207 & 8.6 & 153 & 6.4 & 2,396 & 100.0 \\
\hline $2000-2001$ & 1,793 & 79.9 & 81 & 3.6 & 242 & 10.8 & 128 & 5.7 & 2,244 & 100.0 \\
\hline $2002-2003$ & 1,627 & 79.7 & 75 & 3.7 & 223 & 10.9 & 116 & 5.7 & $2,04 I$ & 100.0 \\
\hline deaths in $30-89$ days & & & & & & & $\dagger$ & & & \\
\hline 1996-1997 & 47 & 10.5 & 121 & 27.0 & 65 & 14.5 & 215 & 48.0 & 448 & 100.0 \\
\hline $1998-1999$ & 50 & 14.6 & 110 & 32.2 & 44 & 12.9 & 138 & 40.4 & 342 & 100.0 \\
\hline $2000-2001$ & 42 & 12.5 & 99 & 29.4 & 63 & 18.7 & 133 & 39.5 & 337 & 100.0 \\
\hline $2002-2003$ & 37 & 11.2 & 115 & 34.8 & 65 & 19.7 & 113 & 34.2 & 330 & 100.0 \\
\hline \multicolumn{11}{|l|}{ deaths in $90-364$ days } \\
\hline 1996-1997 & 4 & 0.4 & 317 & 35.3 & 137 & 15.3 & 439 & 48.9 & 897 & 100.0 \\
\hline $1998-1999$ & 3 & 0.4 & 242 & 33.1 & 110 & 15.0 & 376 & 51.4 & 731 & 100.0 \\
\hline $2000-2001$ & 3 & 0.4 & 247 & 35.2 & 113 & 16.1 & 338 & 48.2 & 701 & 100.0 \\
\hline $2002-2003$ & 5 & 0.8 & 203 & 34.2 & 94 & 15.8 & 292 & 49.2 & 594 & 100.0 \\
\hline \multicolumn{11}{|l|}{ Ages 75+ } \\
\hline deaths in $0-29$ days & $*$ & & $\dagger$ & & $*$ & & $\dagger$ & & & \\
\hline $1996-1997$ & 2,956 & 89.3 & 79 & 2.4 & 87 & 2.6 & 188 & 5.7 & 3,310 & 100.0 \\
\hline $1998-1999$ & 2,869 & 88.5 & 92 & 2.8 & 102 & 3.1 & 178 & 5.5 & $3,24 I$ & 100.0 \\
\hline $2000-2001$ & 2,674 & 86.4 & 118 & 3.8 & 130 & 4.2 & 173 & 5.6 & 3,095 & 100.0 \\
\hline $2002-2003$ & 2,618 & 83.7 & 119 & 3.8 & 168 & 5.4 & 222 & 7.1 & 3,127 & 100.0 \\
\hline \multicolumn{11}{|l|}{ deaths in 30-89 days } \\
\hline $1996-1997$ & 80 & 14.2 & 173 & 30.7 & 45 & 8.0 & 265 & 47.1 & 563 & 100.0 \\
\hline $1998-1999$ & 73 & 12.6 & 170 & 29.3 & 66 & $1 \mathrm{I} .4$ & 271 & 46.7 & 580 & 100.0 \\
\hline $2000-2001$ & 88 & 15.8 & 161 & 28.9 & 61 & 11.0 & 247 & 44.3 & 557 & 100.0 \\
\hline $2002-2003$ & 69 & 12.2 & 161 & 28.4 & 49 & 8.7 & 287 & 50.7 & 566 & 100.0 \\
\hline \multicolumn{11}{|l|}{ deaths in $90-364$ days } \\
\hline $1996-1997$ & 5 & 0.5 & 368 & 33.8 & 103 & 9.5 & 613 & 56.3 & 1,089 & 100.0 \\
\hline $1998-1999$ & 9 & 0.9 & 330 & 31.8 & 114 & 11.0 & 584 & 56.3 & 1,037 & 100.0 \\
\hline $2000-2001$ & 8 & 0.8 & 329 & 31.2 & 96 & 9.1 & 620 & 58.9 & 1,053 & 100.0 \\
\hline $2002-2003$ & 7 & 0.6 & 377 & 34.0 & 88 & 7.9 & 638 & 57.5 & 1,110 & 100.0 \\
\hline
\end{tabular}

* 2-sided chi-square test trend significant $p<.001$.

+2 -sided chi-square test trend significant $p<.05$ 
Table 3: Dutch In-hospital mortality for stroke 1996-2003: deaths tabulated by age and place of death within 30, 90 and 365 days of admission

\begin{tabular}{|c|c|c|c|c|c|c|c|c|c|c|}
\hline \multirow[b]{2}{*}{ Time after admission } & \multicolumn{2}{|c|}{$\begin{array}{r}\text { Deaths during initial } \\
\text { admission }\end{array}$} & \multicolumn{2}{|c|}{$\begin{array}{r}\text { Deaths in same } \\
\text { hospital, during } \\
\text { subsequent } \\
\text { admission }\end{array}$} & \multicolumn{2}{|c|}{$\begin{array}{r}\text { Deaths in a different } \\
\text { hospital }\end{array}$} & \multicolumn{2}{|c|}{$\begin{array}{r}\text { Deaths outside } \\
\text { hospital }\end{array}$} & \multicolumn{2}{|c|}{ All locations } \\
\hline & $\mathbf{N}$ & $\%$ & $\mathbf{N}$ & $\%$ & $\mathbf{N}$ & $\%$ & $\mathbf{N}$ & $\%$ & $\mathbf{N}$ & $\%$ \\
\hline \multicolumn{11}{|l|}{ Ages 35-74 } \\
\hline deaths in 0-29 days & $\dagger$ & & & & & & $\dagger$ & & & \\
\hline $1996-1997$ & 2,609 & 94.0 & 31 & 1.1 & 80 & 2.9 & 56 & 2.0 & 2,776 & 100.0 \\
\hline $1998-1999$ & 2,555 & 94.2 & 32 & 1.2 & 77 & 2.8 & 49 & 1.8 & 2,713 & 100.0 \\
\hline $2000-200 I$ & 2,520 & 93.3 & 28 & 1.0 & 93 & 3.4 & 60 & 2.2 & 2,701 & 100.0 \\
\hline 2002-2003 & 2,463 & 91.8 & 46 & 1.7 & 86 & 3.2 & 87 & 3.2 & 2,682 & 100.0 \\
\hline deaths in $30-89$ days & $*$ & & & & & & $*$ & & & \\
\hline $1996-1997$ & 238 & 44.8 & 94 & 17.7 & 36 & 6.8 & 163 & 30.7 & 531 & 100.0 \\
\hline $1998-1999$ & 192 & 42.0 & 92 & 20.1 & 26 & 5.7 & 147 & 32.2 & 457 & 100.0 \\
\hline $2000-2001$ & 162 & 35.8 & 77 & 17.0 & 35 & 7.7 & 178 & 39.4 & 452 & 100.0 \\
\hline 2002-2003 & 124 & 26.1 & 99 & 20.8 & 31 & 6.5 & 222 & 46.6 & 476 & 100.0 \\
\hline deaths in $90-364$ days & $*$ & & $\dagger$ & & $\dagger$ & & $\dagger$ & & & \\
\hline $1996-1997$ & 38 & 4.3 & 271 & 30.7 & 67 & 7.6 & 506 & 57.4 & 882 & 100.0 \\
\hline $1998-1999$ & 46 & 5.3 & 243 & 28.2 & 82 & 9.5 & 490 & 56.9 & 861 & 100.0 \\
\hline $2000-2001$ & 37 & 4.8 & 189 & 24.5 & 79 & 10.2 & 467 & 60.5 & 772 & 100.0 \\
\hline 2002-2003 & 10 & 1.3 & 194 & 24.7 & 67 & 8.5 & 515 & 65.5 & 786 & 100.0 \\
\hline \multicolumn{11}{|l|}{ Ages 75+ } \\
\hline deaths in 0-29 days & $*$ & & & & & & $*$ & & & \\
\hline $1996-1997$ & 4,239 & 94.7 & 28 & 0.6 & 42 & 0.9 & 168 & 3.8 & 4,477 & 100.0 \\
\hline $1998-1999$ & 4,375 & 94.7 & 30 & 0.6 & 53 & 1.1 & 161 & 3.5 & 4,619 & 100.0 \\
\hline $2000-2001$ & 4,526 & 93.5 & 43 & 0.9 & 74 & 1.5 & 198 & 4.1 & 4,841 & 100.0 \\
\hline 2002-2003 & 4,453 & 90.4 & 59 & 1.2 & 74 & 1.5 & 342 & 6.9 & 4,928 & 100.0 \\
\hline deaths in $30-89$ days & $*$ & & & & $\dagger$ & & $*$ & & & \\
\hline $1996-1997$ & 668 & 52.5 & 97 & 7.6 & 19 & 1.5 & 488 & 38.4 & 1,272 & 100.0 \\
\hline $1998-1999$ & 629 & 50.2 & 102 & 8.1 & 42 & 3.3 & 481 & 38.4 & 1,254 & 100.0 \\
\hline 2000-200I & 641 & 49.1 & 115 & 8.8 & 49 & 3.8 & 501 & 38.4 & 1,306 & 100.0 \\
\hline 2002-2003 & 413 & 29.1 & 143 & 10.1 & 28 & 2.0 & 836 & 58.9 & 1,420 & 100.0 \\
\hline deaths in $90-364$ days & $*$ & & & & & & $*$ & & & \\
\hline $1996-1997$ & 105 & 6.0 & 266 & 15.1 & 60 & 3.4 & 1,328 & 75.5 & 1,759 & 100.0 \\
\hline $1998-1999$ & 184 & 10.4 & 274 & 15.4 & 81 & 4.6 & 1,235 & 69.6 & $\mathrm{I}, 774$ & 100.0 \\
\hline $2000-2001$ & 122 & 6.7 & 274 & 15.1 & 74 & 4.1 & 1,350 & 74.2 & 1,820 & 100.0 \\
\hline 2002-2003 & 37 & 2.0 & 289 & 15.8 & 63 & 3.4 & $\mathrm{I}, 445$ & 78.8 & $\mathrm{I}, 834$ & 100.0 \\
\hline
\end{tabular}

$* 2$-sided chi-square test trend significant $p<.001$.

$\dagger 2$-sided chi-square test trend significant $p<.05$ 
and time of death, with the exception of the proportion of deaths outside the hospital for ages 35-74 within 30-89 days after admission, this fell from $48.0 \%$ in 1996-1997 (215 deaths) to $34.2 \%$ in 2002-2003 (113 deaths).

For stroke a different picture emerges. No significant changes here for deaths in a different hospital, but a significant rise for deaths outside the hospital for both age groups and all three distance to death classes. The rise is especially strong for the proportion of deaths outside the hospital within 30-89 days of admission, and seems to be concentrated in the last years included in the analysis. For instance for deaths of 75+ within 30-89 days after being admitted the proportion of deaths outside the hospital was stable at $38.4 \%$ over $1996-2001$, but rose steeply to $58.9 \%$ in 2002-2003. It is important to note that the observed $30 \%$ fall in average length-of-stay for stroke patients (Table 1) over the period 1996-2003 also occurred mainly in the last four years of this period.

Table 4 (MI) and Table 5 (stroke) list deaths for year of admission, time of death and cause of death. The patterns for both age groups are very similar, so data are presented for 35+. For admissions for MI this shows a significant ( $\mathrm{p}$ $<0.05)$ decrease over time in the proportion of deaths attributed on the death certificate to MI, for all time of death classes. For deaths within 30-days of admission this decrease is accompanied by a significant rise in deaths due to other circulatory disorders and deaths due to other causes. For stroke only for deaths within 90-364 days of admission a similar pattern is found. For deaths due to stroke within 90 days of admission, no significant changes in the distribution of death cases are observed. For both $\mathrm{MI}$ and stroke, the diagnostic groups which contribute the most to 'other causes' are neoplasms, disorders of the endocrine system, and respiratory diseases.

In Table 6 and Table 7, mortality rates are presented for both types of index-admissions and both age-groups. Rates were standardized using the average age and sex composition of the clinical hospital population in 2000 . In addition, we estimated mortality rate changes (as absolute differences between rates) between 1996 and 2003. Most important observation is that all mortality rates have fallen over this period, but the magnitude of this fall differs. For MI, the highest reduction is observed for 30-day

Table 4: Underlying cause of death in people who died after hospital admission for myocardial infarction

\begin{tabular}{|c|c|c|c|c|c|c|c|c|}
\hline \multirow[b]{2}{*}{$\begin{array}{l}\text { Time after } \\
\text { admission }\end{array}$} & \multicolumn{2}{|c|}{ Deaths due to AMI [12I-I22] } & \multicolumn{2}{|c|}{$\begin{array}{r}\text { Deaths due to other circulatory } \\
\text { disorders }\end{array}$} & \multicolumn{2}{|c|}{ Deaths due to other causes } & \multicolumn{2}{|c|}{ all causes } \\
\hline & $\mathbf{N}$ & $\%$ & $\mathbf{N}$ & $\%$ & $\mathbf{N}$ & $\%$ & $\mathbf{N}$ & $\%$ \\
\hline $\begin{array}{l}\text { Ages 35+ } \\
\text { deaths in 0-29 } \\
\text { days }\end{array}$ & $*$ & & $*$ & & $*$ & & & \\
\hline $1996-1997$ & 4,533 & 76.7 & 834 & 14.1 & 544 & 9.2 & 5,911 & 100.0 \\
\hline $1998-1999$ & 4,219 & 74.8 & 863 & 15.3 & 555 & 9.8 & 5,637 & 100.0 \\
\hline 2000-200I & 3,839 & 71.9 & 865 & 16.2 & 635 & 11.9 & 5,339 & 100.0 \\
\hline $2002-2003$ & 3,632 & 70.3 & 900 & 17.4 & 636 & 12.3 & 5,168 & 100.0 \\
\hline $\begin{array}{c}\text { deaths in 30-89 } \\
\text { days }\end{array}$ & $*$ & & & & $\dagger$ & & & \\
\hline $1996-1997$ & 392 & 38.8 & 385 & 38.1 & 234 & 23.1 & 1,011 & 100.0 \\
\hline 1998-1999 & 323 & 35.0 & 384 & 41.6 & 215 & 23.3 & 922 & 100.0 \\
\hline 2000-200I & 310 & 34.7 & 350 & 39.1 & 234 & 26.2 & 894 & 100.0 \\
\hline $2002-2003$ & 263 & 29.4 & 377 & 42.1 & 256 & 28.6 & 896 & 100.0 \\
\hline $\begin{array}{c}\text { deaths in } 90-364 \\
\text { days }\end{array}$ & $*$ & & & & $*$ & & & \\
\hline 1996-1997 & 541 & 27.2 & 804 & 40.5 & 641 & 32.3 & 1,986 & 100.0 \\
\hline $1998-1999$ & 444 & 25.1 & 743 & 42.0 & 581 & 32.9 & 1,768 & 100.0 \\
\hline $2000-2001$ & 394 & 22.5 & 697 & 39.7 & 663 & 37.8 & $\mathrm{I}, 754$ & 100.0 \\
\hline 2002-2003 & 326 & 19.1 & 720 & 42.3 & 658 & 38.6 & I,704 & 100.0 \\
\hline
\end{tabular}

$* 2$-sided chi-square test trend significant $p<.001$.

$\dagger 2$-sided chi-square test trend significant $p<.05$ 
Table 5: Underlying cause of death in people who died after hospital admission for stroke

\begin{tabular}{|c|c|c|c|c|c|c|c|c|}
\hline \multirow[b]{2}{*}{ Time after admission } & \multicolumn{2}{|c|}{$\begin{array}{r}\text { Deaths due to cva [16 I-169] } \\
\text { excl. subarachnoid } \\
\text { hemorrhage }\end{array}$} & \multicolumn{2}{|c|}{$\begin{array}{l}\text { Deaths due to other } \\
\text { circulatory disorders }\end{array}$} & \multicolumn{2}{|c|}{$\begin{array}{r}\text { Deaths due to other } \\
\text { causes }\end{array}$} & \multicolumn{2}{|c|}{ all causes } \\
\hline & $\mathbf{N}$ & $\%$ & $\mathbf{N}$ & $\%$ & $\mathbf{N}$ & $\%$ & $\mathbf{N}$ & $\%$ \\
\hline \multicolumn{9}{|l|}{ Ages 35+ } \\
\hline \multicolumn{9}{|l|}{ deaths in $0-29$ days } \\
\hline $1996-1997$ & 5,395 & 74.4 & 898 & 12.4 & 960 & 13.2 & 7,253 & 100.0 \\
\hline $1998-1999$ & 5,459 & 74.5 & 823 & 11.2 & 1,050 & 14.3 & 7,332 & 100.0 \\
\hline $2000-2001$ & 5,651 & 74.9 & 838 & 11.1 & 1,053 & 14.0 & 7,542 & 100.0 \\
\hline $2002-2003$ & 5,717 & 75.1 & 878 & 11.5 & 1,015 & 13.3 & 7,610 & 100.0 \\
\hline deaths in $30-89$ days & $\dagger$ & & & & & & & \\
\hline $1996-1997$ & 1,070 & 59.3 & 270 & 15.0 & 463 & 25.7 & 1,803 & 100.0 \\
\hline $1998-1999$ & 989 & 57.8 & 265 & 15.5 & 457 & 26.7 & I,7II & 100.0 \\
\hline 2000-200I & 1,012 & 57.6 & 281 & 16.0 & 465 & 26.5 & $\mathrm{I}, 758$ & 100.0 \\
\hline 2002-2003 & 1,036 & 54.6 & 311 & 16.4 & 549 & 29.0 & 1,896 & 100.0 \\
\hline deaths in $90-364$ days & $\dagger$ & & & & $\dagger$ & & & \\
\hline $1996-1997$ & 1,044 & 39.5 & 563 & 21.3 & $\mathrm{I}, 034$ & 39.2 & 2,641 & 100.0 \\
\hline $1998-1999$ & 1,064 & 40.4 & 513 & 19.5 & 1,058 & 40.2 & 2,635 & 100.0 \\
\hline 2000-200I & 1,024 & 39.5 & 514 & 19.8 & 1,054 & 40.7 & 2,592 & 100.0 \\
\hline 2002-2003 & 931 & 35.5 & 529 & 20.2 & 1,160 & 44.3 & 2,620 & 100.0 \\
\hline
\end{tabular}

$* 2$-sided chi-square test trend significant $\mathrm{p}<.001$.

$\dagger 2$-sided chi-square test trend significant $p<.05$

in-hospital mortality. After including readmission and transfer cases, this decrease is much less. For instance, hospital mortality after MI for ages 35-74 has fallen from 7.1 to 5.8 percent, over $1996-2003$, a drop of $1.3 \%$, including other 30-day hospital deaths reduces this to $0.9 \%$. Overall 365 -day mortality dropped by $1.2 \%$, a larger amount than both 30 -day overall mortality $(0.8 \%)$ and 90 -day overall mortality $(0.8 \%)$. For ages $75+$ the picture for $\mathrm{MI}$ is the same, but much higher absolute gains in mortality reduction are found at higher levels of mortality. The 30-day inhospital mortality for $75+$ has dropped from $24.2 \%$ to $20.2 \%$, a drop of $4.1 \%$. Including other 30-day hospital deaths reduces this drop to 3.1\%. Again, 365-day overall mortality dropped by $3.7 \%$ further than 30-day overall mortality (3.1\%) and 90-day mortality (3.4\%). Observed drops in MI-mortality rates occur in most cases gradually over the entire observation period.

For stroke a slightly different picture emerges. Reduction of 30-day mortality within the initial admission is lower than the observed drop for 365 day mortality. For ages 35-74, 30-day mortality within the initial admission has fallen from 12.3 to $11.4 \%$, a drop of $0.9 \%$, while 365 -day overall mortality has fallen with $1.5 \%$. For ages $75+, 30-$ day mortality within the initial admission has fallen from 26.5 to $23.5 \%$, a drop of $3.0 \%$, while 365-day overall mortality has fallen with $3.8 \%$. For stroke, the observed reduction occurs in the last two years of the observation period, but not before.

\section{Discussion}

In our introduction we identified three problems connected to the calculation of mortality indicators: influence of trends in place and time of death on mortality statistics, discrepancy between cause of admission and cause of death and administrative difficulties with the follow-up of patients after discharge.

Some limitations of the study need to be addressed. About $10 \%$ of MI and stroke records could not be linked to population and death registers, because people had administrative twins. However, research by Statistics Netherlands indicates that the influence of this on outcomes is limited [12]. Chances of having an administrative twin are somewhat higher in densely populated areas, and also differ by age. Another limit is of course that available care options are strongly influenced by government regulations, in the Dutch situation for instance the severe restrictions on the 
Table 6: Mortality rates* 1996-2003 after admission for myocardial infarction, for seven different definitions of mortality, as percentage of admissions

\begin{tabular}{|c|c|c|c|c|c|c|}
\hline $\begin{array}{r}\text { 30- day } \\
\text { mortality } \\
\text { initial } \\
\text { admission }\end{array}$ & $\begin{array}{r}\text { 30- day } \\
\text { mortality } \\
\text { initial + } \\
\text { subsequent } \\
\text { admissions }\end{array}$ & $\begin{array}{r}\text { 30-day } \\
\text { mortality all } \\
\text { locations of } \\
\text { death }\end{array}$ & $\begin{array}{r}90-\text { day } \\
\text { mortality } \\
\text { initial + } \\
\text { subsequent } \\
\text { admissions }\end{array}$ & $\begin{array}{r}90-\text { day } \\
\text { mortality all } \\
\text { locations of } \\
\text { death }\end{array}$ & $\begin{array}{r}365-\text { day } \\
\text { mortality } \\
\text { initial + } \\
\text { subsequent } \\
\text { admissions }\end{array}$ & $\begin{array}{r}365-\text { day } \\
\text { mortality all } \\
\text { locations of } \\
\text { death }\end{array}$ \\
\hline
\end{tabular}

a) mortality rates ages $35-74$

\begin{tabular}{|c|c|c|c|c|c|c|c|}
\hline |996-| 997 & 7.1 & 7.7 & 8.1 & 8.3 & 9.3 & 9.5 & 11.5 \\
\hline | $998-1999$ & 6.6 & 7.6 & 8.0 & 8.3 & 9.1 & 9.4 & 11.2 \\
\hline $2000-200 \mathrm{I}$ & 6.5 & 7.6 & 8.0 & 8.3 & 9.0 & 9.4 & 11.2 \\
\hline $2002-2003$ & 5.8 & 6.9 & 7.3 & 7.6 & 8.3 & 8.6 & 10.3 \\
\hline $\begin{array}{l}\text { difference } \\
2003-1996\end{array}$ & -1.3 & -0.9 & -0.8 & -0.8 & -0.9 & -0.9 & -1.2 \\
\hline
\end{tabular}

b) mortality rates ages $75+$

\begin{tabular}{llllllll}
\hline 1996-1997 & 24.2 & 25.6 & 27.1 & 28.1 & 31.8 & 31.8 & 31.0 \\
$1998-1999$ & 23.3 & 24.9 & 26.3 & 27.4 & 31.0 & 39.2 \\
$\mathbf{2 0 0 0 - 2 0 0 1}$ & 21.7 & 23.7 & 25.1 & 26.3 & 29.6 & 29.7 & 38.1 \\
$\mathbf{2 0 0 2 - 2 0 0 3}$ & 20.2 & 22.4 & 24.1 & 24.5 & 28.4 & 36.8 \\
difference & -4.1 & -3.2 & -3.1 & -3.6 & -3.4 & -3.8 & -3.7 \\
$\mathbf{2 0 0 3 - 1 9 9 6}$ & & & & & & \\
\hline
\end{tabular}

*rates standardized for average Dutch hospital population 2000

Table 7: Mortality rates* 1996-2003 after admission for stroke, for seven different definitions of mortality, as percentage of admissions

\begin{tabular}{|c|c|c|c|c|c|c|}
\hline $\begin{array}{r}\text { 30- day } \\
\text { mortality } \\
\text { initial } \\
\text { admission }\end{array}$ & $\begin{array}{r}\text { 30- day } \\
\text { mortality } \\
\text { initial + } \\
\text { subsequent } \\
\text { admissions }\end{array}$ & $\begin{array}{r}30 \text {-day } \\
\text { mortality all } \\
\text { locations of } \\
\text { death }\end{array}$ & $\begin{array}{r}90-\text { day } \\
\text { mortality } \\
\text { initial + } \\
\text { subsequent } \\
\text { admissions }\end{array}$ & $\begin{array}{r}90-\text { day } \\
\text { mortality all } \\
\text { locations of } \\
\text { death }\end{array}$ & $\begin{array}{r}365-\text { day } \\
\text { mortality } \\
\text { initial + } \\
\text { subsequent } \\
\text { admissions }\end{array}$ & $\begin{array}{r}365 \text {-day } \\
\text { mortality all } \\
\text { locations of } \\
\text { death }\end{array}$ \\
\hline
\end{tabular}

a) mortality rates ages $35-74$

\begin{tabular}{|c|c|c|c|c|c|c|c|}
\hline 1996-1997 & 12.3 & 13.0 & 13.3 & 14.5 & 15.4 & 16.1 & 18.8 \\
\hline 1998-1999 & 12.5 & 13.2 & 13.4 & 14.4 & 15.3 & 15.9 & 18.7 \\
\hline 2000-200I & 12.5 & 13.2 & 13.4 & 14.2 & 15.2 & 15.5 & 18.4 \\
\hline $2002-2003$ & 11.4 & 12.1 & 12.4 & 13.1 & 14.3 & 14.2 & 17.3 \\
\hline $\begin{array}{l}\text { difference } \\
2003-1996\end{array}$ & -0.9 & -0.9 & -0.9 & -1.4 & -1.1 & -1.9 & -1.5 \\
\hline
\end{tabular}

b) mortality rates ages $75+$

\begin{tabular}{|c|c|c|c|c|c|c|c|}
\hline |996-1997 & 26.5 & 26.9 & 27.9 & 31.8 & 35.8 & 34.5 & 46.8 \\
\hline 1998-1999 & 26.5 & 27.0 & 27.9 & 31.7 & 35.5 & 35.0 & 46.3 \\
\hline 2000-200 I & 26.3 & 26.9 & 28.0 & 31.6 & 35.5 & 34.4 & 46.1 \\
\hline $2002-2003$ & 23.5 & 24.2 & 26.0 & 27.3 & 33.4 & 29.4 & 43.0 \\
\hline $\begin{array}{l}\text { difference } \\
2003-1996\end{array}$ & -3.0 & -2.7 & -2.0 & -4.5 & -2.5 & -5.1 & -3.8 \\
\hline
\end{tabular}

*rates standardized for average Dutch hospital population 2000 
performance of cardiovascular procedures. However we do think our results may be of wider applicability. For instance our outcomes for place, time and cause of death analysis are for key elements, like the proportion of deaths occurring within the initial admission or the proportion of 30day mortality compared to 1 year mortality, very similar to results of a UK study using data from the Oxford Record Linkage Study [9]. This is remarkable because of the large difference between the tax-funded health care system in the UK and the insurance based system in the Netherlands.

Regarding the question of incorporating transfer cases, we showed that in the Netherlands the proportion of deaths occurring after a transfer has grown for MI, especially for 30-day mortality. The proportion of deaths occurring in another hospital has almost doubled for this group between 1996 and 2003. However, for stroke transfer seems not to be an important issue.

Although it is likely the most severe cases with a high risk of mortality are transferred, it is important to stress that the observed increase over time in post-transfer deaths for MI does not necessarily imply an increase over time in mortality rates for transferred patients. Transfer between hospitals is not a random process but is driven by differences in the availability of resources like IC-units, or a difference in treatment options between hospitals. For instance, in the Netherlands only a minority of hospitals ( 20\%) are allowed to perform percutaneous translumminal coronary angioplasty (PTCA) after a myocardial infarction. Two competing explanations are possible here: mortality rates for cases after transfer are higher because the time between admission and treatment will be longer in general. But mortality rates could also be lower due to better treatment options available in the receiving hospital. Current research like the Prague-1 study $[16,17]$ suggests that the beneficial effects of transfer outweigh negative effects.

The second problem, discrepancy between the cause of hospital admission and the cause of death seems to be an issue growing in importance for deaths after MI but not for stroke. Over the observation period the number of deaths after an MI attributed to another circulatory disease but especially to 'other causes' has grown significantly. The reason for this is unknown. Part of the explanation could be that the accuracy of the death certificates issued after a MI have improved with more cases in which MI can be seen as a complication rather than a primary cause being attributed to the 'true' cause. Another possibility could be a change in diagnostic procedures or in the casemix patients being admitted. Over the period 1996-2003, the age-standardized rate of persons treated in hospital for coronary heart disease fell from 45.4 per 10,000 population to 39.8 per 10,000 (Table 1 ). No such decline is observed for stroke. It could be the case that improved prevention has especially benefited people with a coronary heart disease.

As for the third area, follow-up difficulties, this analysis demonstrates that it is possible to calculate a wide range of hospital mortality indicators using linked morbidity and mortality data.

Using longer time-frames and adding deaths beyond the initial admission increases the number of mortality cases found for both MI and stroke. However, our results show that there is no substantial difference in trends between easily computed 30-day in-hospital mortality, and other indicators which require more effort to compute. All the indicators point to a decline in hospital mortality for MI and stroke for the observed period, with most of the deaths occurring within 30 days of the first admission. For MI it is advisable to exclude transferred cases from the computation of mortality indicators, because of the significant rise of deaths occurring after transport observed over the study period. This is also in line with emerging literature where exclusion of transfer cases does not appear to alter the main conclusions about hospital performance (Peterson et al [18], Bradley et al (19)). For the specific evaluation for the effect of transfer on mortality rates of transferred patients - very likely more severe cases - a separate indicator could be constructed.

Nonetheless, useful insights can be gathered from computing other indicators which cover other places of death beyond index hospitals and longer time frames. Over the observed period, death rates have dropped. It is interesting to observe that the absolute gain improvement in 30-day in-hospital mortality from the period 1996 to 2003 is comparable to the absolute improvement in 365-day mortality (all locations) for MI. This suggests that most of the improvement in survival is reached within the initial hospital treatment period, and that this is a long term effect because no substantial decrease in survival is observed after these first 30 days, which would be the case of there was only a short-term effect of better initial treatment. For stroke the markedly better improved survival rate after one year (as compared to 30-day mortality) indicates that for this condition improvement of care after discharge from the hospital plays a substantial role in the better survival. The almost universal implementation in the last years of our observation period of 'stroke units' in the Netherlands, aimed at optimizing the integration of pre- and post discharge care for stroke, seems to be very successful. For both MI or stroke, there is room for substantial improvement due to secondary prevention after the initial event.

This sheds light on a debate in the Dutch research community [19] about the cause of the declining mortality in the Netherlands for myocardial infarction: better primary 
prevention of hearth disease or better post-myocardial infarction treatment with increased use of angioplasties and drugs like statins.

Since 30-day in-hospital mortality correlates well with other types of mortality, it underlines the continuing importance of this indicator as a measure of hospital performance in terms of MI and stroke treatments they provide.

\section{Conclusion}

More research is needed to link actual hospital processes to these outcome measures, considering the mixed results recently reported in the literature $[18,20]$. Therefore, our study cautions against expecting too much from the use of 30-day in-hospital mortality as an indicator, as our research shows it is well worth to study hospital mortality in the broader context of total mortality, and follow-up mortality over longer time-frames. Although necessary for understanding mortality patterns over time, including within mortality rates deaths which occur outside hospitals and after longer periods following index admissions remain debatable and may not reflect actual hospital performance but probably mirrors transfer, efficiency, and other health care policies.

\section{Competing interests}

The author(s) declare that they have no competing interests.

\section{Authors' contributions}

LCJS performed the analysis, interpreted the results, and drafted the manuscript. OAA designed the study, helped interpret the results, and contributed to the discussion. $\mathrm{AB}$ provided and supervised preparation of data used in the study. GPW supervised the study and participated in the formulation of the discussion. All authors reviewed and edited the manuscript for intellectual content.

\section{Acknowledgements}

Prismant and the Dutch Hospital Association (NVZ) are kindly thanked for granting permission to use the Dutch hospital data. We also thank Statistic Netherlands for the extensive technical assistance in linking and analyzing the data.

\section{References}

I. AHRQ: AHRQ quality indicators; Inpatient Quality Indicators technical specifications. AHRQ; 2002:37.

2. Berg M, Meijerink Y, Gras M, Goossensen A, Schellekens W, Haeck J, Kallewaard M, Kingma $\mathrm{H}$ : Feasibility first: developing public performance indicators on patient safety and clinical effectiveness for Dutch hospitals. Health Policy 2005, 75(I):59-73.

3. Jarman B, Gault S, Alves B, Hider A, Dolan S, Cook A, Hurwitz B, lezzoni LI: Explaining differences in English hospital death rates using routinely collected data. Bmj I999, 3 I8(7 I97): I5 I5- I520.

4. Kosseim M, Mayo NE, Scott S, Hanley JA, Brophy J, Gagnon B, Pilote $\mathrm{L}$ : Ranking hospitals according to acute myocardial infarction mortality: should transfers be included? Med Care 2006, 44(7):664-670.
5. Westfall JM, McGloin J: Impact of double counting and transfer bias on estimated rates and outcomes of acute myocardial infarction. Med Care 200I, 39(5):459-468.

6. Powell AE, Davies HTO, Thomson RG: Using routine comparative data to assess the quality of health care: understanding and avoiding common pitfalls. Qual Saf Health Care \%R I0II36/ qhcl 22 I 22 2003, I2(2): I22-128.

7. Goldacre MJ, Griffith M, Gill L, Mackintosh A: In-hospital deaths as fraction of all deaths within $\mathbf{3 0}$ days of hospital admission for surgery: analysis of routine statistics. Bmj 2002, 324(7345): 1069-1070.

8. Bronnum-Hansen H, Davidsen M, Thorvaldsen P: Long-Term Survival and Causes of Death After Stroke. Stroke 200I, 32(9):2|3|-2|36.

9. Goldacre MJ, Roberts SE, Griffith M: Place, time and certified cause of death in people who die after hospital admission for myocardial infarction or stroke. Eur J Public Health 2004, 14(4):338-342.

10. IGZ: Het resultaat telt 2005. Dutch health care Inspectorate (IGZ); 2006.

II. Jong SD: Klopt dat wel? prestatieindicatoren nader bekeken. In Faculteit gezondheidswetenschappen Maastricht, Universiteit maastricht; 2006:73.

12. De Bruin A, Kardaun JWPF, Gast A, De Bruin El, van Sijl M, Verweij GCG: Record linkage of hospital discharge register with population register: Experiences at Statistics Netherlands. Statistical Journal of the United Nations Economic Commission for Europe 2004, 2I(I):23-32.

13. Reitsma JB, Kardaun JWPF, Gevers E, De Bruin A, van der Wal J, Bonsel G: Possibilities for anonymous follow-up studies of patients in Dutch national medical registrations using the Municipal Population Register: a pilot study. [in dutch]. Ned Tijdschr Geneesk 2003, I 47:2286-2290.

14. De Bruin A, De Bruin EI, Gast A, Kardaun JWPF, Van Sijl M, Verweij GCG: Koppeling van LMR- en GBA-gegevens: methode, resultaten en kwaliteitsonderzoek. Voorburg/Heerlen , Statistics Netherlands (CBS); 2003:38.

15. SMR: Classificatie van ziekten 1980. Utrecht, Stichting Medische Registratie; 1980.

16. Bednar F, Widimsky P, Krupicka J, Groch L, Aschermann M, Zelizko $M$ : Interhospital transport for primary angioplasty improves the long-term outcome of acute myocardial infarction compared with immediate thrombolysis in the nearest hospital (one-year follow-up of the PRAGUE-I study). Can J Cardiol 2003, 19(10): II33-1137.

17. Widimsky P, Budesinsky T, Vorac D, Groch L, Zelizko M, Aschermann M, Branny M, St'asek J, Formanek P: Long distance transport for primary angioplasty vs immediate thrombolysis in acute myocardial infarction. Final results of the randomized national multicentre trial--PRAGUE-2. Eur Heart J 2003, 24(1):94-104.

18. Peterson ED, Roe MT, Mulgund J, DeLong ER, Lytle BL, Brindis RG, Smith SC Jr., Pollack CV Jr., Newby LK, Harrington RA, Gibler WB, Ohman EM: Association between hospital process performance and outcomes among patients with acute coronary syndromes. Jama 2006, 295(16):1912-1920.

19. Roeters van Lennep JE, Van der Wall EE: Decline in hospital admissions for coronary heart diseases. Nederlands Tijdschrift Geneeskunde 2004, 148(1):7-9.

20. Bradley EH, Herrin J, Elbel B, McNamara RL, Magid DJ, Nallamothu BK, Wang Y, Normand SL, Spertus JA, Krumholz HM: Hospital quality for acute myocardial infarction: correlation among process measures and relationship with short-term mortality. Jama 2006, 296(I):72-78.

21. CBS statline [http://statline.cbs.nl]

\section{Pre-publication history}

The pre-publication history for this paper can be accessed here:

http://www.biomedcentral.com/1472-6963/8/52/prepub 